\title{
Rare-earth elements in human colostrum milk
}

\author{
Barbara Poniedzialek ${ }^{1} \cdot$ Pawel Rzymski ${ }^{2}$ Malgorzata Pięt ${ }^{2} \cdot$ Przemyslaw Niedzielski $^{3}$. \\ Miroslaw Mleczek ${ }^{4} \cdot$ Maciej Wilczak $^{2} \cdot$ Piotr Rzymski $^{1}$
}

Received: 24 March 2017 / Accepted: 28 September 2017 / Published online: 19 October 2017

(C) The Author(s) 2017. This article is an open access publication

\begin{abstract}
Rare-earth elements (REEs) are used in a growing number of applications, and their release to environment has increased over the decades. Knowledge of REEs in human milk and factors that could possibly influence their concentration is scarce. This study evaluated the concentrations of 16 REEs (Ce, Eu, Er, Gd, La, Nd, Pr, Sc, Sm, Dy, Ho, Lu, Tb, $\mathrm{Tm}, \mathrm{Y}$, and $\mathrm{Yb}$ ) in human colostrum milk collected from Polish women $(n=100)$ with the ICP-OES technique. The concentrations (mean $\pm \mathrm{SD}$ ) of $\operatorname{Pr}\left(41.9 \pm 13.2 \mu \mathrm{g} \mathrm{L}^{-1}\right), \mathrm{Nd}$ $\left(11.0 \pm 4.0 \mu \mathrm{g} \mathrm{L}^{-1}\right), \mathrm{La}\left(7.1 \pm 5.2 \mu \mathrm{g} \mathrm{L}^{-1}\right)$, and $\mathrm{Er}$ $\left(2.2 \pm 0.8 \mu \mathrm{g} \mathrm{L}^{-1}\right)$ were found above detection limits. The total mean \pm SD concentration of detected REEs was $60.9 \pm 17.8 \mu \mathrm{g} \mathrm{L}^{-1}$. Current smokers displayed significantly increased $\mathrm{Nd}$ concentrations compared to women who had never smoked. No other associations between REEs in colostrum milk and age, diet in pregnancy (food supplement use and frequency of fish, meat, and vegetable consumption) or place of living (urban/rural) were found. This study adds to general understanding of the occurrence and turnover of REEs in women and human fluids.
\end{abstract}

Responsible editor: Philippe Garrigues

Piotr Rzymski

rzymskipiotr@ump.edu.pl

1 Department of Environmental Medicine, Poznan University of Medical Sciences, Poznań, Poland

2 Department of Mother's and Child's Health, Gynecologic and Obstetrical University Hospital, Poznan University of Medical Sciences, Poznań, Poland

3 Department of Analytical Chemistry, Faculty of Chemistry, Adam Mickiewicz University, Poznań, Poland

4 Department of Chemistry, Poznan University of Life Sciences, Poznań, Poland
Keywords Rare-earth elements · Human colostrum milk · Breastfeeding · Inductively coupled plasma optical emission spectrometry

\section{Introduction}

Breastfeeding is considered the most desirable source of infant nutrition, currently recommended to be exclusively practiced for the first 6 months of life (World Health Organization 2003). Human milk is a rich source of macro- and micronutrients, and a unique matrix of bioactive compounds that contribute to the development of intestinal microbiota, immune maturation, and organ development (Ballard and Morrow 2013; Walker and Iyengar 2015). However, its chemical composition may be prone to alterations driven by the maternal lifestyle, diet, and exposure to contaminants (Čechová et al. 2016; Napierala et al. 2016; Grzunov Letinić et al. 2016; Torregrosa Paredes et al. 2014).

Despite the body of knowledge on the concentration of trace elements in human milk collected from various stages of lactation (Bates and Prentice 1994; Krachler et al. 1998; Grzunov Letinić et al. 2016), not much is known on the occurrence of rare-earth elements (REEs). They represent an emerging group of pollutants whose emissions, and consequently exposures, have increased over recent decades due to certain human activities (Pagano et al. 2015). Therefore, it is imperative that their content in different types of biological material be systematically investigated, yet information in this regard is still scarce.

The group of REEs consists of lanthanum (La), cerium (Ce), europium (Eu), gadolinium (Gd), neodymium (Nd), praseodymium $(\mathrm{Pr})$, promethium $(\mathrm{Pm})$, samarium $(\mathrm{Sm})$, scandium (Sc) categorized as light REEs (LREEs), and dysprosium (Dy), erbium (Er), holmium (Ho), lutetium (Lu), terbium (Tb), thulium $(\mathrm{Tm})$, yttrium $(\mathrm{Y})$, and ytterbium $(\mathrm{Yb})$ representing 
heavy REEs (HREEs). A sheer number of REE applications in the industrial, medical, and agricultural sector have been developed over recent decades, resulting in their increasing environmental spread (Pagano et al. 2015). The data concerning the toxicity of REEs is mostly limited to $\mathrm{Nd}, \mathrm{La}, \mathrm{Ce}$, and $\mathrm{Gd}$, and is based predominantly on animal studies and observations of occupational human exposures with no comprehensive observation on the effects of long-term exposure (Pagano et al. 2015). It is however known that REEs can accumulate in humans at increased levels in certain populations at higher exposure risk, e.g., those residing in the vicinity of mining areas (Li et al. 2013; Wei et al. 2013; Hao et al. 2015; Rzymski et al. 2017a). A recent study linked REE levels in hair with higher a risk of hypertension in women (Wang et al. 2017). Diet may constitute an important route of human exposure to REEs. Various food products, including vegetables and mushrooms were found to contain REEs at a total content tending to exceed $0.7 \mathrm{mg} \mathrm{kg}^{-1}$ fresh weight (Li et al. 2013; Siwulski et al. 2017; Rzymski et al. 2017b; Zhuang et al. 2017) which is the maximum threshold set in China, the only country yet to regulate REEs in foodstuffs (SAC 2012).

Bearing this in mind, there is an emerging need to determine levels of REEs in breast milk and to evaluate whether humans can be exposed to these elements in early stages of postnatal life. At present, there is little data available; concentrations of a few elements of both groups (mostly Ce, La, Pt, and Sc) in human milk have previously been reported from studies conducted on a generally small sample size (Friel et al. 1999). The present research was undertaken in an effort to broaden knowledge on REEs. To this end, a screening of their concentrations in colostrum milk collected from total of hundred Polish women using inductively coupled plasma optical emission spectrometry (ICP-OES) was conducted. Additionally, the potential relations between the level of elements and maternal characteristics were assessed. This study may serve as a reference point for further studies on REEs in human milk and add to the general understanding of the occurrence and turnover of these elements in the human body and exposure during the early stages of neonatal development.

\section{Material and methods}

\section{Study participants}

The study was conducted in 2016. The milk was collected from women who had been admitted to the Gynecologic and Obstetrical University Hospital in Poznań (Poland) and were giving birth. The milk was taken 3 days after parturition, during the initiation of lactation. The inclusion criteria included birth by spontaneous delivery or cesarean section, no chronic maternal disease, no breast disease, or inflammation requiring topical administration of drugs. Exclusion criteria included history of muskeloskeletal, or other disease requiring metalbased or artificial material implantation, no surgery with metal-based stapler use, chronic renal, gastrointestinal, endocrine (except previously treated and stable hypothyroidism in the euthryreosis stage), genetic, muskeloskeletal, metabolic, neural, psychiatric, pulmonary, or cardiological disease. All mothers who had not developed sufficient colostrum secretion to collect samples for the study were also excluded.

Based on a short questionnaire, the place of living, smoking habits, and diet during pregnancy (use of pregnancy food supplements, frequency of fish, meat, and vegetable consumption) were specified for the investigated women. The study was approved by the Local Bioethical Committee of the Poznan University of Medical Sciences, Poznan, Poland and every recruited female undersigned a written consent.

\section{Milk collection}

Colostrum milk (15-20 mL) was collected using a manual breast pump suction device from women who did not experience any difficulties in milk secretion. No high under pressure, breast massage, or topical/systemic drugs were used to stimulate milk secretion. Milk was collected directly into a $20-\mathrm{mL}$ syringe (B. Braun, USA) by a professional lactation consultant (International Board Certified Lactation Consultant IBCLC no. 309-75569) between 8:00 and 12:00 a.m. during postpartum hospitalization. After collection, the milk samples were frozen at $-40{ }^{\circ} \mathrm{C}$ prior to further procedures.

\section{Analytical procedures}

Milk samples were thawed to room temperature on a shaker and thoroughly homogenized by vigorous shaking. Afterwards, $1 \mathrm{~mL}$ of milk was digested with $3 \mathrm{~mL}$ of $\mathrm{HNO}_{3}$ in closed Teflon vessels using the microwave sample digestion system Mars 6 (CEM, USA). The digestion procedure consisted of two steps: ramp to temperature $180{ }^{\circ} \mathrm{C}$ for $20 \mathrm{~min}$ and hold at $180{ }^{\circ} \mathrm{C}$ for $30 \mathrm{~min}$. After digestion, the solution was diluted to a final volume of $5.0 \mathrm{~mL}$ with ultrapure water obtained in the Milli-Q system (Millipore, USA).

The concentration of 16 REEs (Ce, Eu, Er, Gd, La, Nd, Pr, Sc, Sm, Dy, Ho, Lu, Tb, Tm, Y, and Yb) was determined using the inductively coupled plasma optical emission spectrometer Agilent 5100 ICP-OES (Agilent, USA). The following common instrumental parameters were used for determination of all elements: RF power $1.2 \mathrm{~kW}$, plasma gas (argon) flow $12 \mathrm{~L} \mathrm{~min}^{-1}$, nebulizer gas (argon) flow $0.7 \mathrm{~L} \mathrm{~min}^{-1}$, radial view height $8 \mathrm{~mm}$ for the synchronous view (dual axial and radial plasma view). The following wavelengths were used for REE determination: Ce-446.021 nm, Dy-400.045 nm, $\mathrm{Er}-349.910 \mathrm{~nm}, \mathrm{Eu}-420.504 \mathrm{~nm}, \mathrm{Gd}-342.246 \mathrm{~nm}$, Ho-348.484 nm, La-333.749 nm, Lu-307.760 nm, 
Nd $-406.108 \mathrm{~nm}, \operatorname{Pr}-417.939 \mathrm{~nm}, \mathrm{Sc}-361.383 \mathrm{~nm}, \mathrm{Sm}-$ $442.434 \mathrm{~nm}, \mathrm{~Tb}-350.914 \mathrm{~nm}, \mathrm{Tm}-336.261 \mathrm{~nm}, \mathrm{Y}-$ $361.104 \mathrm{~nm}, \mathrm{Yb}-328.937 \mathrm{~nm}$, respectively. ICP commercial analytical standards CM17 PrimAg Plus and KP7 PrimAg (Romil, England) were applied for the calibration.

The detection limits for elements determined were found at the level of $0.001 \mu \mathrm{g} \mathrm{L}^{-1}$. Due to a lack of matrix-certified reference materials for elemental analysis of human milk, traceability control was approached in two ways. Firstly, the certified standard material CRM NCSDC 73349 (bush branches and leaves) was used for method validation. Recovery values ranging from 75 to $125 \%$ were considered as satisfactory. Secondly, the standard addition procedure was applied. Recovery at the level of $80-120 \%$ was also accepted as satisfactory.

\section{Statistical analyses and calculations}

The statistical analyses were performed in Statistica, version 13.0 (StatSoft, U.S.A.). Because the data did not meet the assumption of Gaussian distribution (Shapiro-Wilk test, $p<.05$ ), non-parametric methods were employed to test the results. Responses given for the frequency of meat, fish, and vegetable consumption were transposed onto a sixpoint ordinal scale $(0$ - never; 5 -very often). Differences in element concentrations between the two groups were assessed with the Mann-Whitney $U$ test. Correlations between two datasets were evaluated with Spearman's rank correlation coefficient (Rs). A value of $p<0.05$ was considered statistically significant. The homogeneity of REEs presence in investigated samples of milk was presented for each element in the form of graph showing the elements normalized to the value of 1.0 .

\section{Results}

\section{Demographic characteristics}

The study analyzed colostrum milk collected from a total of 100 women. Their demographic characteristics are summarized in Table 1.

\section{Rare-earth elements in milk}

From the sixteen REEs investigated in this study, only four were identified: $\mathrm{Er}, \mathrm{La}, \mathrm{Nd}$, and Pr. Their mean milk concentration generally decreased in the following order: $\mathrm{Pr}>\mathrm{Nd}>\mathrm{La}>\mathrm{Er}$ (Table 2). A number of significant positive correlations were found between the identified REEs; the strongest were observed between Pr and other identified REEs (Table 3). The vast majority of studied milk samples revealed relative
Table 1 Demographic characteristics of the studied mothers and their neonates $(n=100)$

Maternal characteristics

\begin{tabular}{|c|c|c|}
\hline Age (years) & $($ Mean $\pm \mathrm{SD})$ & $31.2 \pm 5.6$ \\
\hline$<30$ years old & $n$ & 31 \\
\hline$>30$ years old & $n$ & 69 \\
\hline Body mass index before pregnancy & $($ Mean $\pm \mathrm{SD})$ & $22.9 \pm 5.0$ \\
\hline Underweight $(<18.5)$ & $n$ & 12 \\
\hline Normal weight (18.5-24.9) & $n$ & 61 \\
\hline Overweight (25.0-29.9) & $n$ & 21 \\
\hline Obese $(>30.0)$ & $n$ & 6 \\
\hline Weight gain during pregnancy & $($ Mean \pm SD) & $13.7 \pm 4.5$ \\
\hline $\begin{array}{l}\text { Weight gain as } \% \text { of body mass } \\
\text { before pregnancy }\end{array}$ & & $22.1 \pm 8.4$ \\
\hline \multicolumn{3}{|l|}{ Place of living } \\
\hline Urban & $n$ & 71 \\
\hline Rural & $n$ & 29 \\
\hline \multicolumn{3}{|l|}{ Smoking history } \\
\hline Non-smokers & $n$ & 60 \\
\hline Current smokers & $n$ & 3 \\
\hline Former smokers & $n$ & 37 \\
\hline Years of smoking & $($ Mean $\pm \mathrm{SD})$ & $6.6 \pm 3.7$ \\
\hline Cigarettes per day among smokers & $($ Mean $\pm \mathrm{SD})$ & $7.5 \pm 5.7$ \\
\hline Years after cessation & $($ Mean \pm SD $)$ & $2.9 \pm 2.6$ \\
\hline \multicolumn{3}{|l|}{ Diet (frequency of food consumption) } \\
\hline \multicolumn{3}{|l|}{ Fish } \\
\hline Never & $n$ & 2 \\
\hline Rarely & $n$ & 36 \\
\hline Moderate & $n$ & 45 \\
\hline Very often & $n$ & 16 \\
\hline \multicolumn{3}{|l|}{ Meat } \\
\hline Never & $n$ & 2 \\
\hline Rarely & $n$ & 8 \\
\hline Moderate & $n$ & 28 \\
\hline Often & $n$ & 37 \\
\hline Very often & $n$ & 25 \\
\hline \multicolumn{3}{|l|}{ Vegetable } \\
\hline Very rarely & $n$ & 1 \\
\hline Rarely & $n$ & 2 \\
\hline Moderate & $n$ & 9 \\
\hline Often & $n$ & 31 \\
\hline Very often & $n$ & 57 \\
\hline Pregnancy food supplement use & $n$ & 83 \\
\hline
\end{tabular}

SD standard deviation

homogeneity of REEs occurrence as presented graphically after normalization of concentration to the value of 1.0 (Fig. 1).

No significant correlations between REE content and maternal age was found and no difference in their concentration was observed between groups of females $<30$ and $>30$ years 
Table 2 Concentrations $\left(\mu \mathrm{g} \mathrm{L}^{-1}\right)$ of rare-earth elements (REEs) in human breast milk $(n=100)$

\begin{tabular}{lcccc}
\hline & \% samples $>$ LOD & Mean \pm SD & Median & Max \\
\hline \multicolumn{5}{c}{ REEs } \\
Er & 52 & $2.2 \pm 0.8$ & 2.1 & 4.5 \\
$\mathrm{La}$ & 100 & $7.1 \pm 5.2$ & 6.1 & 51 \\
$\mathrm{Nd}$ & 99 & $11.0 \pm 4.0$ & 11.3 & 22.7 \\
$\mathrm{Pr}$ & 100 & $41.9 \pm 13.2$ & 40.8 & 78.9 \\
Total REEs & 100 & $61.4 \pm 17.5$ & 61.5 & 106.0 \\
\hline
\end{tabular}

old $(p>0.05)$. Total mean REEs content in these groups amounted to $61.7 \pm 16.3$ and $61.2 \pm 18.1 \mu \mathrm{g} \mathrm{L}^{-1}$, respectively. Similarly, BMI and weight gain during pregnancy were not significantly correlated with the concentration of any of REE in milk ( $p>0.05$ for all) nor did their concentration differ between particular BMI groups ( $p>0.05$ all).

Concentration of REEs in colostrum milk was not found to be correlated with frequency of meat, fish, and vegetable consumption, and did not differ between women using and not using food supplements during pregnancy $(p>0.05$ all).

With the exception of higher $\mathrm{Nd}$ concentrations found in the milk of current smokers ( $n=3$; Fig. 2), the level of REEs for current and former smokers did not differ significantly from that of females who had never smoked $(p>0.05$ for all). Mean total concentrations of REEs for these groups were $67.3 \pm 29.5,59.1 \pm 18.6$, and $62.4 \pm 17.2 \mu \mathrm{g} \mathrm{L}^{-1}$. Smoking frequency, years of smoking, and years since smoking ceased were not related to the content of any element $(p>0.05$ for all) although the level of $\mathrm{La}$ in the milk of former smokers was positively correlated with the number of cigarettes smoked per day $(\mathrm{Rs}=0.35, p<0.05)$.

There was no significant difference in the content of any REE in colostrum milk between mothers inhabiting rural and urban areas; mean total REE concentration amounted to $59.9 \pm$ 17.3 and $62.0 \pm 17.7 \mu \mathrm{g} \mathrm{L}^{-1}$, respectively $(p>0.05)$. Additionally, no differences were detected when only normal BMI, never-smoking women inhabiting urban $(n=27)$ and rural $(n=12)$ areas were compared $(p>0.05$ for all); total mean REE concentration was $59.7 \pm 15.0$ and $63.0 \pm 18.4 \mu \mathrm{g} \mathrm{L}^{-1}$.

Table 3 Spearman's rank correlation coefficient (Rs) for rare-earth elements determined in human colostrum milk

\begin{tabular}{llll}
\hline & $\mathrm{La}$ & $\mathrm{Nd}$ & $\mathrm{Pr}$ \\
\hline $\mathrm{Er}$ & $0.32 * *$ & $0.38^{* * *}$ & $0.46^{* * *}$ \\
$\mathrm{La}$ & - & 0.19 & $0.53 * * *$ \\
$\mathrm{Nd}$ & - & $0.50^{* * * *}$ \\
$\mathrm{Pr}$ & & & - \\
\hline
\end{tabular}

$* * p<0.01, * * * p<0.001$

\section{Discussion}

The present study provides new information regarding REEs in breast milk and lays a foundation for further research on the occurrence of these elements in humans as well as the factors influencing their presence. Given the fact that the likelihood of exposure to the studied elements has significantly increased over recent decades, and that at least some REEs can exert toxic effects, screening their content in human milk is important in view of newborn care and safety. It should be stressed that information on REEs occurrence in Poland is relatively scarce and relates to investigations of farmer's well water, acid mine drainage, fungi (concentrations in ppb range), soil, rocks, and moss (concentrations in ppm range) collected nearby mining areas (Dołęgowska and Migaszewski 2013; Migaszewski et al. 2014; Mleczek et al. 2016). To date, no biomonitoring research on REEs was conducted in Polish population. However, as previously reported in China, human aged $<60$ years accumulate mainly light REEs (Wei et al. 2013). In accordance with this observation, $\mathrm{Pr}$, La, and Nd, the most abundant REEs determined in human colostrum milk, belong to the group of light REEs. In turn, Er was the only heavy REEs that was found above detection limits but only in about half of samples collected in this study. It should be stressed that concentrations $(\mathrm{Pr}>\mathrm{Nd}>\mathrm{La}>\mathrm{Er}$ ) found in human milk did not follow their average abundance in Earth's crust ( $\mathrm{La}>\mathrm{Nd}>\mathrm{Pr}>\mathrm{Er}$ ) (Tyler and Olsson 2001) indicating possible regulatory and/or exclusion processes before and/or after exposure.

Concentrations of the majority of REEs (Ce, Eu, Gd, Sc, $\mathrm{Sm}, \mathrm{Dy}, \mathrm{Ho}, \mathrm{Lu}, \mathrm{Tb}, \mathrm{Tm}, \mathrm{Y}$, and $\mathrm{Yb}$ ) milk were, however, below detection limits of employed ICP-OES method. Recent human biomonitoring studies have reported that urine and hair contain detectable levels of all REEs (Wei et al. 2013; Hao et al. 2015; Wang et al. 2017), and one could expect a similar result for breast milk. The mammary gland is, however, known to regulate concentrations of essential elements to avoid their deficiency or excess in milk, both harmful to a newborn (Lönnerdal 2007), and that such concentrations are not associated with maternal status (Domellöf et al. 2004). It is unknown whether this mechanism may also occur for the elements investigated in the present research; this would require further investigations on relation between REEs concentrations in milk and other biological samples (e.g., urine, serum, plasma, hair, or nails).

To date, only a few studies have assessed the concentrations of selected REEs ( $\mathrm{La}$ and $\mathrm{Ce}$ ) in a limited number of human milk samples. A study by Friel et al. 1999 reported La content at around $5 \mu \mathrm{g} \mathrm{L}^{-1}$ which is consistent with our findings. Similar values were reported for Ce (Friel et al. 1999), an element found below detection in the present study. Colostrum milk has been previously shown to contain significantly higher concentrations of various trace elements, 
Fig. 1 Graphical presentation of homogeinity of detected REEs in investigated human colostrum milk. Concentrations of Er, La, $\mathrm{Nd}$, and Pd were normalized to the value of 1.0

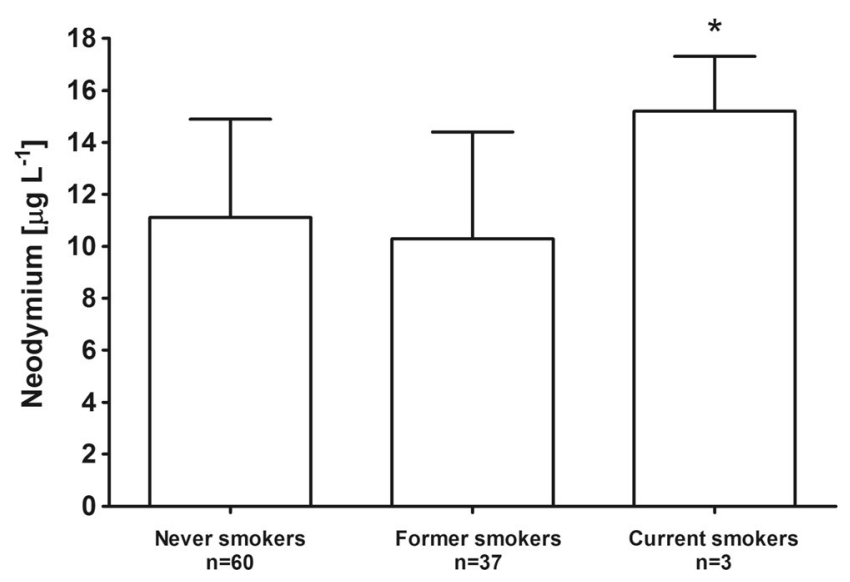

Fig. 2 Mean $( \pm \mathrm{SD})$ concentrations of $\mathrm{Nd}$ in human colostrum milk in relation to maternal smoking status. Asterisk indicates significant difference with colostrum milk concentrations of never-smoking women $(p<0.05$; Mann-Whitney $U$ test $)$

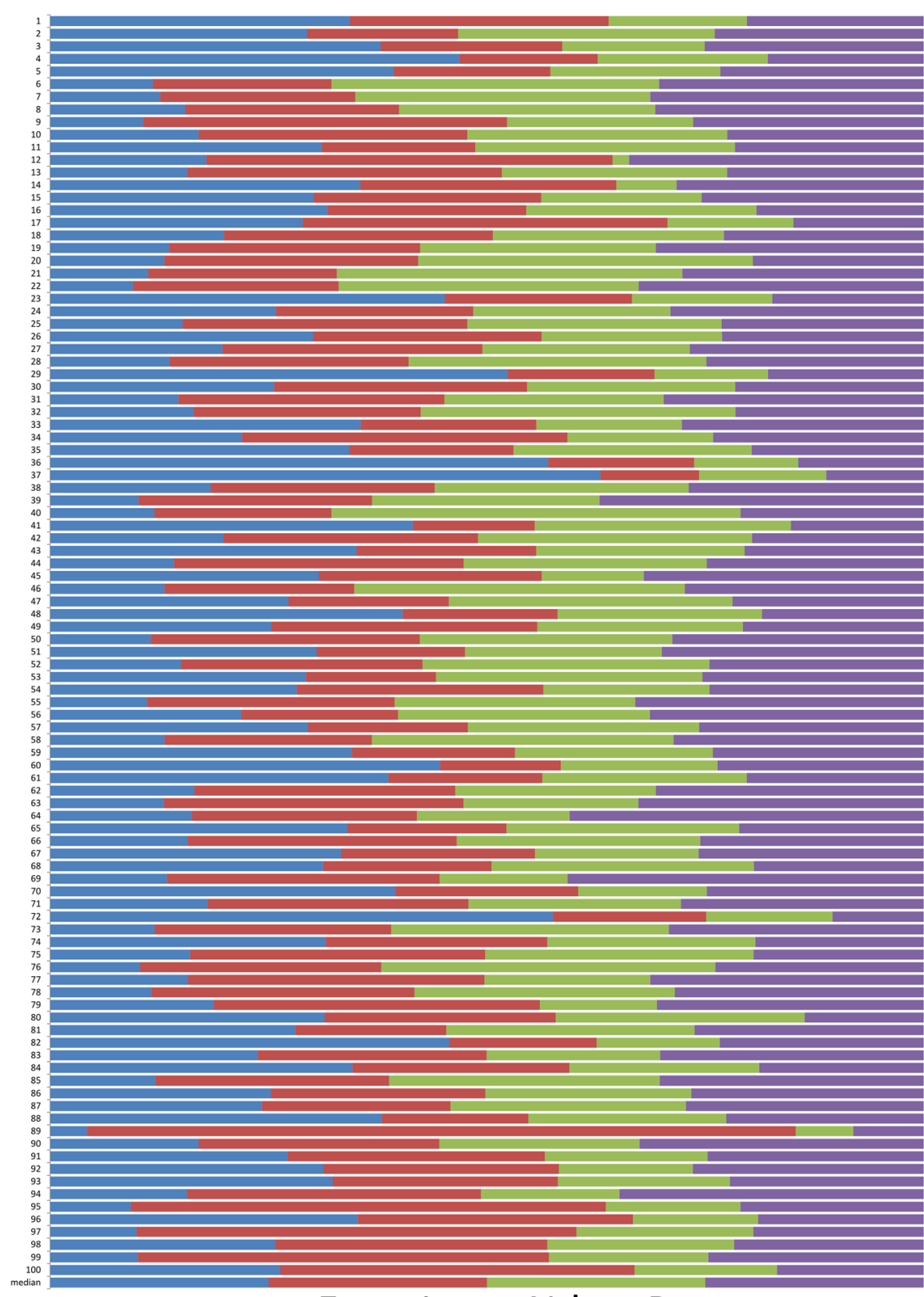

$\square \mathrm{Er} \square \mathrm{La} \square \mathrm{Nd} \square \mathrm{Pr}$

including essential and toxic ones, than transitional or mature breast milk (Akanle et al. 2001; Chao et al. 2014).

The associations between smoking and exposure to REEs are generally poorly recognized and require further attention. There is no reliable data on concentrations of these elements in cigarettes and cigarette smoke although high levels of La and Ce have been found in indoor places with high tobaccosmoking activity (Bolte et al. 2008; Böhlandt et al. 2012). A recent investigation has shown that concentrations of $\mathrm{La}, \mathrm{Ce}$, and $\mathrm{Gd}$ in semen increase with smoking duration (MarzecWróblewska et al. 2015). An important issue in the bioaccumulation of some of the toxic elements present in cigarette smoke is their possible systematic release, even after smoking cessation. As previously shown, women who have formerly smoked tend to have increased cadmium and lead levels in their reproductive system (Rzymski et al. 2016a; Rzymski 
et al. 2016b), and higher levels of cadmium in milk when compared to never-smokers (García-Esquinas et al. 2011).

As found in the present study, former smoking was not associated with increased levels of REEs in breast milk. Although the significantly increased concentration of Nd observed for currently smoking women is worth further attention, one should bear in mind the small group size $(n=3)$. A human biomonitoring study conducted in 2010 in China did not find any association between the smoking habit and $\mathrm{Nd}$ levels though current and former smokers had higher concentrations of LREEs (of which $\mathrm{Nd}$ is one of seven representatives) in morning urine (Hao et al. 2015). As evidenced experimentally, exposure to $\mathrm{Nd}$ can cause cytotoxicity and genetic damage through oxidative stress (Palmer et al. 1987; Jha and Singh 1995; Huang et al. 2011), although it is unknown whether $\mathrm{Nd}$ poses any threat in the concentrations found in the colostrum milk of smoking women.

As demonstrated by previous research, concentrations of REEs in human body reflect their environmental levels (Brown et al. 2004; Wei et al. 2013). Considering that important sources of REEs are emissions from vehicles (Wang et al. 2001), a reasonable approach was to compare their concentrations in milk collected from mothers inhabiting urban and rural areas. The increased REEs concentrations in human have been so far associated with mining and smelting areas (Wei et al. 2013; Hao et al. 2015; Wang et al. 2017). However, urban populations have been shown to reveal elevated levels of certain pollutants such as arsenic, mercury, platinum group elements, cadmium, and lead in blood, tissue, urinary, and hair (Iavicoli et al. 2007; Rzymski et al. 2015; Roca et al. 2016; Rzymski et al. 2016b). The present study did not detect any statistically significant differences in the content of REEs in colostrum milk in relation to inhabited area. Again, these results may preliminarily suggest that secretion of REEs to human milk is tightly regulated and not prone to environmental exposures. This hypothesis would however require further research thoroughly assessing the exposure of women to REEs from various sources including certain foods and emissions. For example, coal fly ashes have been found to be relatively rich in REEs (particularly light REEs), and if one considers that Poland is the second greatest coal consumer in the European Union (Franus et al. 2015), fumes from coal-burning may represent an important and chronic route of exposure to these elements in Polish population, and potentially a source of their further bioaccumulation and distribution in human body.

\section{Conclusion}

This study reports the occurrence of four REEs ( $\mathrm{Pr}, \mathrm{Nd}, \mathrm{La}$, and $\mathrm{Er}$ ) in human breast milk at low concentrations (ppb range). The other elements of these groups were below detection limits. As indicated, increased $\mathrm{Nd}$ concentrations may potentially be linked to maternal smoking. No differences in REEs concentration were found between mothers living in urban and rural areas. Considering the increased emissions of studied elements over recent decades, and the possibilities of human exposure, there is an urgent need to conduct more research on their occurrence in human milk, associated factors, and potential outcomes.

Acknowledgements The authors kindly thank all the mothers (and their children!) for donating their milk for this research. Piotr Rzymski is supported by the Foundation for Polish Science within the "Start" Program (091.2016).

Compliance with ethical standards The study was approved by the Local Bioethical Committee of the Poznan University of Medical Sciences, Poznan, Poland and every recruited female undersigned a written consent.

Open Access This article is distributed under the terms of the Creative Commons Attribution 4.0 International License (http:// creativecommons.org/licenses/by/4.0/), which permits unrestricted use, distribution, and reproduction in any medium, provided you give appropriate credit to the original author(s) and the source, provide a link to the Creative Commons license, and indicate if changes were made.

\section{References}

Akanle OA, Balogun FA, Owa JA, Spyrou NM (2001) Variations in trace element concentrations in breast milk in stages of lactation. $\mathrm{J}$ Radioanal Nucl Chem 249:71-75

Ballard O, Morrow AL (2013) Human milk composition: nutrients and bioactive factors. Pediatr Clin N Am 60:49-74

Bates CJ, Prentice A (1994) Breast milk as a source of vitamins, essential minerals and trace elements. Pharmacol Ther 62:193-220

Böhlandt A, Schierl R, Diemer J, Koch C, Bolte G, Kiranoglu M, Fromme H, Nowak D (2012) High concentrations of cadmium, cerium and lanthanum in indoor air due to environmental tobacco smoke. Sci Total Environ 414:738-741

Bolte G, Heitmann D, Kiranoglu M, Schierl R, Diemer J, Koerner W, Fromme H (2008) Exposure to environmental tobacco smoke in German restaurants, pubs and discotheques. J Expo Sci Environ Epidemiol 18:262-271

Brown CJ, Chenery SR, Smith B, Mason C, Tomkins A, Roberts GJ, Sserunjogi L, Tiberindwa JV (2004) Environmental influences on the trace element content of teeth-implications for disease and nutritional status. Arch Oral Biol 49:705-717

Čechová E, Scheringer M, Seifertová M, Mikeš O, Kroupová K, Kuta J, Forns J, Eggesbø M, Quaak I, de Cock M, van de Bor M, Patayová H, Palkovičová Murínová L', Kočan A (2016) Developmental neurotoxicants in human milk: comparison of levels and intakes in three European countries. Sci Total Environ. https://doi.org/10. 1016/j.scitotenv.2016.11.046

Chao HH, Guo CH, Huang CB, Chen PC, Li HC, Hsiung DY, Chou YK (2014) Arsenic, cadmium, lead, and aluminium concentrations in human milk at early stages of lactation. Pediatr Neonatol 55(2): $127-134$

Dołęowska S, Migaszewski ZM (2013) Anomalous concentrations of rare earth elements in the moss-soil system from south-central Poland. Environ Pollut 178:33-40 
Domellöf M, Lönnerdal B, Dewey KG, Cohen RJ, Hernell O (2004) Iron, zinc, and copper concentrations in breast milk are independent of maternal mineral status. Am J Clin Nutr 79:111-115

Franus W, Wiatros-Motyka MM, Wdowin M (2015) Coal fly ash as a resource for rare earth elements. Environ Sci Pollut Res Int 22: 9464-9474

Friel JK, Andrews WL, Jackson SE, Longerich HP, Mercer C, McDonald A, Dawson B, Sutradhar B (1999) Elemental composition of human milk from mothers of premature and full-term infants during the first 3 months of lactation. Biol Trace Elem Res 67:225-247

García-Esquinas E, Pérez-Gómez B, Fernández MA, Pérez-Meixeira AM, Gil E, de Paz C, Iriso A, Sanz JC, Astray J, Cisneros M, de Santos A, Asensio A, García-Sagredo JM, García JF, Vioque J, Pollán M, López-Abente G, González MJ, Martínez M, Bohigas PA, Pastor R, Aragonés N (2011) Mercury, lead and cadmium in human milk in relation to diet, lifestyle habits and sociodemographic variables in Madrid (Spain). Chemosphere 85:268-276

Grzunov Letinić J, Matek Sarić M, Piasek M, Jurasović J, Varnai VM, Sulimanec Grgec A, Orct T (2016) Use of human milk in the assessment of toxic metal exposure and essential element status in breastfeeding women and their infants in coastal Croatia. J Trace Elem Med Biol 38:117-125

Hao Z, Li Y, Li H, Wei B, Liao X, Liang T, Yu J (2015) Levels of rare earth elements, heavy metals and uranium in a population living in Baiyun Obo, Inner Mongolia, China: a pilot study. Chemosphere 128:161-170

Huang P, Li J, Zhang S, Chen C, Han Y, Liu N, Xiao Y, Wang H, Zhang M, Yu Q, Liu Y, Wang W (2011) Effects of lanthanum, cerium, and neodymium on the nuclei and mitochondria of hepatocytes: accumulation and oxidative damage. Environ Toxicol Pharmacol 31:25-32

Iavicoli I, Bocca B, Carelli G, Caroli S, Caimi S, Alimonti A, Fontana L (2007) Biomonitoring of tram drivers exposed to airborne platinum, rhodium and palladium. Int Arch Occup Environ Health 81:109 114

Jha AM, Singh AC (1995) Clastogenicity of lanthanides: induction of chromosomal aberration in bone marrow cells of mice in vivo. Mutat Res 341:193-197

Krachler ML, Li FS, Rossipal E, Irgolic KJ (1998) Changes in the concentrations of trace elements in human milk during lactation. J Trace Elem Med Biol 12:159-176

Li X, Chen Z, Chen Z, Zhang Y (2013) A human health risk assessment of rare earth elements in soil and vegetables from a mining area in Fujian Province, Southeast China. Chemosphere 93:1240-1246

Lönnerdal B (2007) Trace element transport in the mammary gland. Annu Rev Nutr 27:165-177

Marzec-Wróblewska U, Kamiński P, Łakota P, Ludwikowski G, Szymański M, Wasilow K, Stuczyński T, Buciński A, Jerzak L (2015) Determination of rare earth elements in human sperm and association with semen quality. Arch Environ Contam Toxicol 69: 191-201

Migaszewski ZM, Gałuszka A, Migaszewski A (2014) The study of rare earth elements in farmer's well waters of the Podwiśniówka acid mine drainage area (south-central Poland). Environ Monit Assess $1609-1622$

Mleczek M, Niedzielski P, Kalač P, Siwulski M, Rzymski P, Gąsecka M (2016) Levels of platinum group elements and rare-earth elements in wild mushroom species growing in Poland. Food Addit Contam A 33:86-94

Napierala M, Mazela J, Merritt TA, Florek E (2016) Tobacco smoking and breastfeeding: effect on the lactation process, breast milk composition and infant development. A critical review. Environ Res 151:321-338

Pagano G, Aliberti F, Guida M, Oral R, Siciliano A, Trifuoggi M, Tommasi F (2015) Rare earth elements in human and animal health: state of art and research priorities. Environ Res 142:215-220

Palmer RJ, Butenhoff JL, Stevens JB (1987) Cytotoxicity of the rare earth metals cerium, lanthanum, and neodymium in vitro: comparisons with cadmium in a pulmonary macrophage primary culture system. Environ Res 43:142-156

Roca M, Sánchez A, Pérez R, Pardo O, Yusà V (2016) Biomonitoring of 20 elements in urine of children. Levels and predictors of exposure. Chemosphere 144:1698-1705

Rzymski P, Tomczyk K, Rzymski P, Poniedziałek B, Opala T, Wilczak M (2015) Impact of heavy metals on the female reproductive system. Ann Agric Environ Med 22(2):259-264

Rzymski P, Niedzielski P, Poniedziałek B, Tomczyk K, Rzymski P (2016a) Identification of toxic metals in human embryonic tissues. Arch Med Sci. https://doi.org/10.5114/aoms.2015.53915

Rzymski P, Niedzielski P, Rzymski P, Tomczyk K, Kozak L, Poniedziałek B (2016b) Metal accumulation in the human uterus varies by pathology and smoking status. Fertil Steril 105:1511-1518

Rzymski P, Klimaszyk P, Marszelewski W, Borowiak D, Mleczek M, Nowiński K, Pius B, Niedzielski P, Poniedziałek B (2017a) The chemistry and toxicity of discharge waters from copper mine tailing impoundment in the valley of the Apuseni Mountains in Romania. Environ Sci Pollut Res Int 24:21445-21458

Rzymski P, Mleczek M, Siwulski M, Jasińska A, Budka A, Niedzielski P, Kalac P, Gąsecka M, Budzyńska S (2017b) Multielemental analysis of fruit bodies of three cultivated commercial Agaricus species. J Food Compos Anal 59:170-178

SAC (2012) Standardization Administration of the People's Republic of China. Maximum levels of contaminants in foods; GB 2762-2012

Siwulski M, Mleczek M, Rzymski P, Budka A, Jasińska A, Niedzielski P, Kalac P, Gąsecka M, Budzyńska S, Mikołajczak P (2017) Screening the multi-element content of pleurotus mushroom species using inductively coupled plasma optical emission spectrometer (ICP-OES). Food Anal Methods 10:487-496

Torregrosa Paredes P, Gutzeit C, Johansson S, Admyre C, Stenius F, Alm J, Scheynius A, Gabrielsson S (2014) Differences in exosome populations in human breast milk in relation to allergic sensitization and lifestyle. Allergy 69:463-471

Tyler G, Olsson T (2001) Concentrations of 60 elements in the soil solution as related to the soil acidity. Eur J Soil Sci 52:151-165

Walker WA, Iyengar RS (2015) Breast milk, microbiota, and intestinal immune homeostasis. Pediatr Res 77:220-228

Wang CX, Zhu W, Peng A, Guichreit R (2001) Comparative studies on the concentration of rare earth elements and heavy metals in the atmospheric particulate matter in Beijing, China, and in Delft, The Netherlands. Environ Int 26:309-313

Wang B, Yan L, Huo W, Lu Q, Cheng Z, Zhang J, Li Z (2017) Rare earth elements and hypertension risk among housewives: a pilot study in Shanxi Province, China. Environ Pollut 220:837-842

Wei B, Li Y, Li H, Yu J, Ye B, Liang T (2013) Rare earth elements in human hair from a mining area of China. Ecotoxicol Environ Saf 96: $118-123$

World Health Organization (2003) Infant and young child nutrition. World Health Organization, Geneva

Zhuang M, Zhao J, Li S, Liu D, Wang K, Xiao P, Yu L, Jiang Y, Song J, Zhou J, Wang L, Chu Z (2017) Concentrations and health risk assessment of rare earth elements in vegetables from mining area in Shandong, China. Chemosphere 168:578-582 